\title{
A phase II trial of TIP (paclitaxel, ifosfamide and cisplatin) given as second-line (post-BEP) salvage chemotherapy for patients with metastatic germ cell cancer: a medical research council trial
}

\section{GM Mead ${ }^{*, 1}$, MH Cullen ${ }^{2}$, R Huddart ${ }^{3}$, P Harper ${ }^{4}$, GJS Rustin ${ }^{5}$, PA Cook ${ }^{6}$, SP Stenning ${ }^{6}$ and M Mason ${ }^{7}$ on behalf of the MRC Testicular Tumour Working Party ${ }^{8}$}

'Medical Oncology Unit, C Level West Wing, Southampton General Hospital, Southampton SOI6 6YD, UK; '² University Hospital Birmingham NHS Foundation Trust, Birmingham BI5 2TH, UK; ${ }^{3}$ Royal Marsden Hospital, Sutton SM2 5PT, UK; ${ }^{4}$ Guy's Hospital, London SEI 9RT, UK; ${ }^{5}$ Mt Vernon Hospital, Harrow HA6 2RN, UK; ${ }^{6}$ MRC Clinical Trials Unit, London NWI 2DA, UK; 7 Velindre Hospital, Cardiff CF4 7XL, UK

This phase II trial describes the use of TIP chemotherapy (paclitaxel, ifosfamide and cisplatin) as salvage for patients with metastatic germ cell cancer (GCC) who have failed initial BEP (bleomycin, etoposide and cisplatin) chemotherapy. Patients with first relapse following BEP for metastatic GCC, confirmed by biopsy or sequentially rising markers, received four courses of TIP (paclitaxel $175 \mathrm{mg} \mathrm{m}^{-2}$ day I, followed on days I -5 by ifosfamide $1 \mathrm{~g} \mathrm{~m}^{-2}$ intravenously (i.v.) and cisplatin $20 \mathrm{mg}^{2}$ i.v.) at 3-weekly intervals. The primary outcome measure was response to TIP. In all, 5 I patients were registered, of whom 43 were eligible for response assessment. Eight achieved complete remission (CR) and 18 a partial remission with negative markers (PR ${ }^{-v e}$ ); favourable response rate $\left(F R R=C R+P R^{-v e}\right) 60 \%, 95 \% \mathrm{Cl}(44-75 \%)$; survival at I year was 70\% (56-84\%) and failure-free survival 36\% (22-50\%). In the group of 26 patients meeting the 'good-risk' criteria described by the Memorial Hospital, the FRR was 73\% (52-88\%) compared with $41 \%$ (18-67\%) for the 17 'poor-risk' patients. These results are inferior to those previously reported for TIP in a single-centre study when it was given more intensively, at higher dose and with growth factor support. Nonetheless, TIP as described here can cure a substantial proportion of patients.

British Journal of Cancer (2005) 93, 178- 184. doi:10.1038/sj.bjc.6602682 www.bjcancer.com

Published online 5 July 2005

(c) 2005 Cancer Research UK

Keywords: cisplatin; ifosfamide; metastatic germ cell cancer; paclitaxel; salvage chemotherapy

Approximately $85 \%$ of patients with newly diagnosed metastatic germ cell cancer (GCC) will be cured when treated with a cisplatincontaining regimen \pm surgery; BEP (bleomycin etoposide and cisplatin) is currently the worldwide standard treatment. The remaining $15 \%$ of patients require salvage treatment and are a relatively heterogeneous group. A proportion may be salvaged surgically, predominantly patients with recurrent mature teratoma or with a late relapse (Baniel et al, 1995; Gerl et al, 1997). However, most will require chemotherapy.

Two treatment approaches have been used in this population: standard-dose chemotherapy given alone, or standard dose in combination with high-dose chemotherapy plus autologous stem cell rescue. A preliminary analysis of a single randomised trial comparing these approaches has been reported and has shown no difference in survival (Rosti et al, 2002).

A variety of prognostic factors determine outlook in these patients (Motzer et al, 1991; Gerl et al, 1995; Miller et al, 1997;

\footnotetext{
*Correspondence: Dr GM Mead; E-mail: Ben.Mead@suht.swest.nhs.uk

${ }^{8}$ Now National Cancer Research Institute Testis Cancer Clinical Studies Group. For full list of participants, see Appendix AI.

Received 10 March 2005; revised 26 May 2005; accepted 27 May 2005; published online 5 July 2005
}

Loehrer et al, 1998; Fossa et al, 1999). The Memorial Hospital Group (MSKCC) divided their population into two groups with a good or poor prognosis (Motzer et al, 1991, 2000a, b; Donadio et al, 2003). The former group, defined by the presence of a testicular primary, $\leqslant 6$ cycles of cisplatin-containing chemotherapy and initial complete response or partial response with normal tumour markers, was evaluated in a phase II study of TIP (paclitaxel, ifosfamide and cisplatin (Motzer et al, 2000b). Initial and updated (Donadio et al, 2003) results suggest high efficacy for this treatment approach in this group of patients.

The multi-institution study described here has evaluated TIP given at modified dose in a salvage setting to all prognostic groups and has compared the results with the MSKCC salvage chemotherapy experience.

\section{PATIENTS AND METHODS}

\section{Eligibility}

Male patients with the following characteristics were eligible: (i) first relapse after previous BEP chemotherapy given for metastatic GCC, (ii) either sequentially rising serum markers (AFP and/or HCG) or biopsy-proven and unresectable GCC; (iii) age 16-65 
years; (iv) ECOG performance status $0-2$; (v) glomerular filtration rate of $\geqslant 50 \mathrm{ml} \mathrm{h}^{-1}$ and (vi) no evidence of brain metastases.

\section{Patient registration}

Following informed consent, patients were registered by telephoning the MRC Clinical Trials Unit (CTU), London prior to starting treatment. Exceptionally, patients could be registered during the first cycle of TIP if urgent treatment was required and weekends or public holidays prevented earlier registration. The treatment protocol was approved by both national and local Research Ethics Committees.

\section{Treatment}

TIP comprised paclitaxel $175 \mathrm{mg} \mathrm{m}^{-2}$ given intravenously (i.v.) over $3 \mathrm{~h}$ after appropriate premedication on day 1 , followed on days $1-5$ by ifosfamide $1 \mathrm{~g} \mathrm{~m}^{-2}$ i.v. over $1 \mathrm{~h}$ with mesna $500 \mathrm{mg} \mathrm{m}^{-2}$. Following this infusion, a further $500 \mathrm{mg} \mathrm{m}^{-2}$ of mesna was given in $1 \mathrm{l}$ of normal saline over $8 \mathrm{~h}$ as part of cisplatin hydration. Patients also received cisplatin $20 \mathrm{mg} \mathrm{m}^{-2}$ i.v. on days 1-5 with appropriate pre- and postcisplatin hydration.

TIP was recommenced on day 22 using the following dose reduction schedule for ifosfamide and paclitaxel: total WBC $>2.0 \times 10^{9} 1^{-1}$ and platelets $>100 \times 10^{9} 1^{-1}$ or WBC $>3.0 \times 10^{9} 1^{-1}$ and platelets $75-100 \times 10^{9} 1^{-1}$; full doses of all drugs. Total WBC $>1.5 \times 10^{9} 1^{-1}$ and platelets $50-100 \times 10^{9} 1^{-1} ; 75 \%$ dose ifosfamide and paclitaxel. Total WBC $1.5-2 \times 10^{9} 1^{-1}$ and platelets $50-75 \times 10^{9} 1^{-1} ; 50 \%$ dose ifosfamide and paclitaxel.

Patients with lower blood counts had chemotherapy deferred for 3 days and were treated according to the above schedule on recovery of counts. No dose modifications were made based on previous treatment cycles. Granulocyte colony-stimulating factor (G-CSF) was given at the discretion of the investigator, but was recommended for all future cycles following an episode of neutropenic sepsis.

Cisplatin was given at full dose unless the creatinine clearance fell below $40 \mathrm{ml} \mathrm{min}^{-1}$, in which case it was discontinued. If the creatinine clearance recovered subsequently to above this level, cisplatin was initially recommenced at $75 \%$ dose. Routine supportive care was offered for neutropenic fever and thrombocytopenia according to the protocols then in use in each institution.

\section{Clinical evaluation}

All patients initially underwent full physical examination together with assessment of the tumour markers AFP, HCG and LDH. Chest $\mathrm{X}$-ray and CT scans of the head, chest, abdomen and pelvis were performed together with routine biochemistry and a 24-h creatinine clearance (or EDTA). During treatment, the AFP and HCG levels were monitored together with chest X-rays. At the completion of chemotherapy, a new CT scan was performed. Marker negative patients with residual resectable masses were assessed surgically and, wherever feasible, these were completely excised.

\section{Response assessment and toxicity evaluation}

All patients had to complete at least one course of chemotherapy before being eligible for response evaluation. Following chemotherapy and/or surgery, the following criteria were defined by the protocol. Complete remission (CR): normal AFP and HCG levels; no radiological evidence of residual tumour masses or, if surgery was performed, complete excision of mature teratoma or necroticl fibrotic tissue. Incomplete response (IR): persistent elevation of tumour markers or viable cancer seen in surgically resected specimens (including those which were completely resected).
Treatment failure: rising tumour markers or radiological progression during chemotherapy. Partial remission, marker negative; $\left(\mathrm{PR}^{-\mathrm{ve}}\right)$ : normal tumour markers at completion of chemotherapy but nonresectable/resected residual tumour masses. Additionally, the category $\mathrm{CR}(\mathrm{S})$ has been used to identify IR patients with no evidence of disease following complete resection of viable malignancy. Failure-free survival (FFS) events were defined as follows: IR/failure of TIP at response assessment (time of failure was taken to be day 1) excluding $\mathrm{CR}(\mathrm{S})$ patients; relapse after CR, $\mathrm{CR}(\mathrm{S})$ or $\mathrm{PR}^{-\mathrm{ve}}$ (time of failure was taken to be date of relapse confirmation); and death from any cause (time of failure was date of death, if no prior FFS event observed). Patients without an FFS event were censored at the last assessment date, or start of consolidation chemotherapy $(n=2)$. Survival was measured from the date of initiation of chemotherapy to date of death or date last seen. Toxicity was evaluated using the NCIC Common Toxicity Criteria (v2).

\section{Consolidation therapy and follow-up}

In this multicentre study, a number of group members reserved the right to consolidate the treatment results attained with TIP by use of either high-dose chemotherapy with stem cell rescue or involvedfield radiotherapy (this latter approach was used predominantly for patients with seminoma and residual masses). High-dose therapy was used less frequently as the study progressed.

On completion of treatment, it was recommended that patients be seen every 2 months during the first year, every 3 months in year 2, every 4 months in year 3, every 6 months in year 4 and annually thereafter.

\section{Statistical considerations}

The primary outcome measure was CR rate after four cycles of TIP. The study was originally designed to accrue, in a single-stage design, 25 patients assessable for response allowing the CR rate to be estimated with a standard error of $\leqslant 10 \%$. A CR rate of $\geqslant 60 \%$ with acceptable toxicity was regarded as a suitable target for use of this combination in further studies. After this study commenced, the MSKCC Group published a study using the same drugs, although at different dose, in their good prognosis subgroup (Motzer et al, 2000b; Donadio et al, 2003). With approval from the independent Trial Steering Committee, we continued our study until we had accrued 25 patients matching these favourable prognosis criteria to see if we could achieve comparable results.

Response rates, FFS and overall survival rates are given with 95\% confidence intervals. FFS and overall survival rates are presented as Kaplan-Meier curves.

\section{RESULTS}

\section{Patient characteristics}

In all, 51 male patients from 14 UK centres were registered between April 1998 and October 2002. Initial accrual was slow as the trial was confined to patients relapsing after initial induction with BEP within MRC trial TE20 (de Wit et al, 2001), and only later expanded to include any patient relapsing after BEP. Of the 51 patients, 43 were entered after this change, in July 2000.

Eight of the 51 patients (16\%) were excluded from the primary analysis. Seven were ineligible: four had normal markers with no biopsy confirmation of active cancer, one had brain metastases, one was treated as adjuvant following complete resection of active cancer and one was registered too late (during the third cycle of chemotherapy)). In addition, one patient developed an anaphylactic reaction to paclitaxel in the first treatment cycle and was thereby withdrawn from the study, and inevaluable for response. 
All the following results relate to the 43 eligible patients (26 good prognosis (Motzer et al, 2000b), 17 poor prognosis (Motzer et al, 2000a)) whose characteristics are shown in Table 1 . The population

Table I Patient characteristics at study entry $(n=43)$

\begin{tabular}{|c|c|c|}
\hline & Number of patients & $\%$ \\
\hline \multicolumn{3}{|l|}{ Primary site } \\
\hline Testis & 37 & 86.00 \\
\hline Mediastinal & 3 & 7.00 \\
\hline Retroperitoneal & । & 2.30 \\
\hline Not known & 2 & 4.70 \\
\hline \multicolumn{3}{|l|}{ Age (years) } \\
\hline Median & 34 & \\
\hline Minimum & 20 & \\
\hline Maximum & 51 & \\
\hline \multicolumn{3}{|l|}{ Histology } \\
\hline Seminoma & 9 & 20.90 \\
\hline Nonseminoma & 33 & 76.70 \\
\hline Not known (high HCG, no biopsy) & । & 2.30 \\
\hline \multicolumn{3}{|l|}{ Sites } \\
\hline Abdominal & 24 & 55.80 \\
\hline Mediastinal & 9 & 20.90 \\
\hline Supraclavicular & 6 & 14.00 \\
\hline Lung & 14 & 32.60 \\
\hline Pleura & 2 & 4.70 \\
\hline Mesenteric & 2 & 4.70 \\
\hline Markers only & 3 & 7.00 \\
\hline Liver & I & 2.30 \\
\hline Bone & 1 & 2.30 \\
\hline Kidney & 1 & 2.30 \\
\hline Inguinal nodes & 1 & 2.30 \\
\hline Pelvis & 1 & 2.30 \\
\hline \multicolumn{3}{|l|}{ BHCG $\left(I \cup I^{-1}\right)$} \\
\hline Median & 28 & \\
\hline Minimum & Normal & \\
\hline Maximum & 9944 & \\
\hline \multicolumn{3}{|l|}{$\operatorname{AFP}\left(K \cup I^{-1}\right)$} \\
\hline Median & 4 & \\
\hline Minimum & Normal & \\
\hline Maximum & 89000 & \\
\hline \multicolumn{3}{|l|}{$\mathrm{LDH}\left(\mathrm{IU} I^{-1}\right)$} \\
\hline Median & 391 & \\
\hline Minimum & 133 & \\
\hline Maximum & 4534 & \\
\hline \multicolumn{3}{|l|}{ Relapse interval } \\
\hline$<2$ months & 4 & 9.30 \\
\hline 2 months to 2 years & 30 & 69.80 \\
\hline$>2$ years & 9 & 20.90 \\
\hline
\end{tabular}

comprised four patients with early relapse (entering this study $\leqslant 2$ months after the start of their last cycle of BEP), nine with late relapse ( $\geqslant 2$ years from completion of $\mathrm{BEP}$ ) and the remaining 30 patients with intermediate relapse. Histology was nonseminoma in $33(77 \%)$, and $37(86 \%)$ had a gonadal primary.

\section{Chemotherapy delivery}

In all, 36 patients (84\%) received all four cycles of TIP, five patients received three cycles and one patient two cycles. The final patient received five cycles of TIP, the final cycle being given in error. The median (range) time between treatment cycles $1-2,2-3$ and 3-4, respectively, were 21 days $(19-33), 21$ days $(19-28)$ and 21 days $(15-49)$. The proportion of patients receiving $>85 \%$ of the individual drugs were $80.5 \%$ for cisplatin, $78.1 \%$ for ifosfamide and $78.1 \%$ for paclitaxel. The median (range) relative dose intensity (actual daily dose intensity divided by planned, full dose, dose intensity over four courses of treatment) was $0.97(0.58-1.02)$ for cisplatin, $1.03(0.58-0.95)$ for ifosfamide and $0.95(0.63-1.03)$ for paclitaxel.

\section{Toxicity}

One toxic death occurred following the third TIP cycle, the patient dying from staphylococcal septicaemia while neutropenic. Grade 3 or 4 leucopenia was recorded in $64 \%$ of patients, neutropenia in $70 \%$ of patients and thrombocytopenia in $35 \%$ of patients; 12 patients (28\%) had granulocytopenic fever (with neutrophils $\left.<1.0 \times 10^{9} 1^{-1}\right)$.

\section{Response rates, FFS and survival}

Eight patients (19\%) achieved CR, seven from TIP alone, one from TIP and complete resection of a necrotic mass. In total, $18(42 \%)$ achieved $\mathrm{PR}^{-\mathrm{ve}}$ (one had resection of one mass with others observed). Five patients (12\%) had CR(S) (of whom two went on to receive adjuvant etoposide). Eight patients (19\%\%) had IR (of whom two underwent partial resections and one a complete resection of one of several metastatic sites) and three (7\%) treatment failure/early death (one of whom had complete resection of one of several metastatic sites). The favourable response rate as defined by the protocol $\left(\mathrm{FRR}_{\mathrm{p}}=\mathrm{CR}+\mathrm{PR}^{-\mathrm{ve}}\right)$ was $60 \%, 95 \% \mathrm{CI}$ (44-75\%). Including $\mathrm{CR}(\mathrm{S})$ patients in the favourable response category $\left(\mathrm{FRR}_{\mathrm{c}}\right)$, the $\mathrm{FRR}_{\mathrm{c}}=72 \%(56-85 \%)$.

The corresponding figures according to MSKCC risk group are shown in Table 2; the overall $\mathrm{FRR}_{\mathrm{p}}$ was $73 \%(52-88 \%)$ for the good-risk patients and $41 \%(18-67 \%)$ for the poor-risk group. The $\mathrm{FRR}_{\mathrm{p}}(95 \% \mathrm{CI})$ for the three groups early $(n=4)$, intermediate $(n=30)$ and late relapse $(n=9)$ were, respectively, $0 \%(0-60 \%)$, $67 \%(47-83 \%)$ and $67 \%(30-93 \%)$.

Adjunctive treatment was given to seven patients (six of whom were in the favourable prognosis group). Four (three seminoma, one mixed tumour) achieved $P R^{-v e}$ status and received radiotherapy

Table 2 Response rates, FFS and overall survival

\begin{tabular}{|c|c|c|c|c|c|c|c|c|c|}
\hline \multirow[b]{2}{*}{ Group } & \multicolumn{5}{|c|}{ Response (N, \%) } & \multirow[b]{2}{*}{$\begin{array}{c}\text { Favourable } \\
(\mathrm{CR}+\mathrm{PR}) \\
\text { response rate } \\
\left(\text { FFR }_{\mathrm{p}}\right)(95 \% \mathrm{CI})\end{array}$} & \multirow[b]{2}{*}{$\begin{array}{c}\text { Favourable } \\
(\mathrm{CR}+\mathrm{PR}+\mathrm{CR}(\mathrm{S})) \\
\text { response rate } \\
\left(\mathrm{FFR}_{\mathrm{c}}\right)(95 \% \mathrm{CI})\end{array}$} & \multirow[b]{2}{*}{$\begin{array}{l}\text { I-year } \\
\text { FFS rate } \\
(95 \% \mathrm{CI})\end{array}$} & \multirow[b]{2}{*}{$\begin{array}{l}\text { I-year overall } \\
\text { survival rate } \\
(95 \% \mathrm{CI})\end{array}$} \\
\hline & CR & PR MK-ve & $\begin{array}{c}\text { Complete resection } \\
\text { of viable malignancy } \\
\text { CR(S) }\end{array}$ & IR & $\begin{array}{c}\text { Treatment } \\
\text { failure/early } \\
\text { death }\end{array}$ & & & & \\
\hline All patients & $8(19 \%)$ & $18(42 \%)$ & $5(12 \%)$ & $8(19 \%)$ & $4(9 \%)$ & $60 \%(44-75)$ & $72 \%(56-85)$ & $38 \%(23-53)$ & $70 \%(56-84)$ \\
\hline MSKCC good risk & $7(27 \%)$ & $12(46 \%)$ & $2(8 \%)$ & $3(12 \%)$ & $2(8 \%)$ & $73 \%(52-88)$ & $81 \%(6 \mid-93)$ & $43 \%(23-63)$ & $81 \%(64-98)$ \\
\hline MSKCC poor risk & I (6\%) & $6(35 \%)$ & $3(18 \%)$ & $5(29 \%)$ & $2(12 \%)$ & $41 \%(18-67)$ & $59 \%(33-82)$ & $29 \%(8-5 I)$ & $53 \%(29-77)$ \\
\hline
\end{tabular}

$\mathrm{CR}=$ complete response; $\mathrm{PR}=$ partial response; $\mathrm{IR}=$ incomplete response; $\mathrm{FFS}=$ failure-free survival; $95 \% \mathrm{Cl}=95 \%$ confidence interval. 
to residual masses; one achieved $\mathrm{PR}^{-\mathrm{ve}}$ status but proceeded to high-dose therapy with stem cell support; one patient had an IR (complete resection of viable tumour) and was given adjuvant oral etoposide and finally one patient had an IR (partial resection of viable tumour) and had further high-dose chemotherapy. All seven patients remain alive and progression free.

In all, $28 \mathrm{FFS}$ events have occurred comprising one early toxic death, $11 \mathrm{IR} /$ failure to TIP (nine have died, one is alive with active disease, one is alive and disease free), four relapses after CR(S) (three have died, one is alive with active disease) and 12 relapses after CR or $\mathrm{PR}^{-\mathrm{ve}}$ (five have died, four are alive with active disease, three are alive and disease free). Thus, 19 patients are alive and disease free, six are alive with active disease and 18 have died. Of the four patients currently disease free following an FFS event, salvage therapy was high-dose chemotherapy (two patients), gemcitabine + cisplatin (one patient) and surgery + radiotherapy (one patient). The median follow-up time of the 25 survivors is 26 months (range 11-70 months).

Overall FFS and FFS by MSKCC risk groups are shown in Table 2 and Figures 1 and 2. The overall FFS rate at 1 year is $38 \%$ (95\% CI 23-53\%); the corresponding rates for the good- and poorrisk subgroups are $43 \%(23-63 \%)$ and $29 \%(8-51 \%)$, respectively.

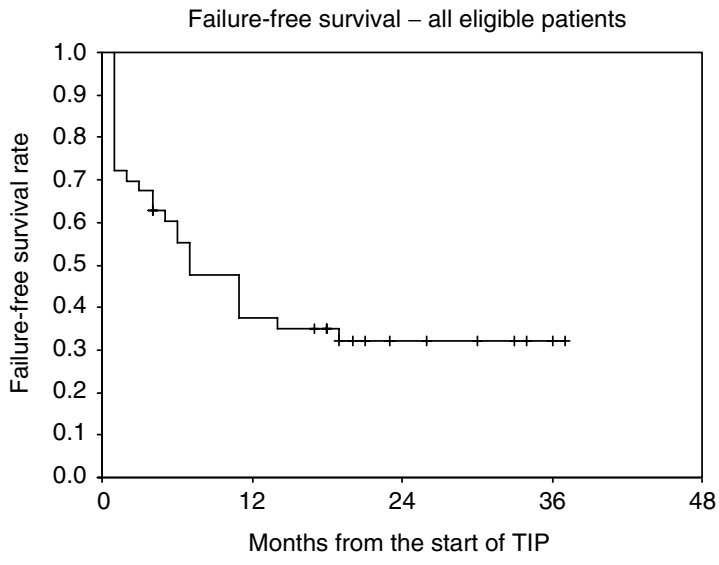

Numbers at risk

$\begin{array}{lllll}43 & 15 & 6 & 2 & 0\end{array}$

Figure I Failure-free survival, all eligible patients.

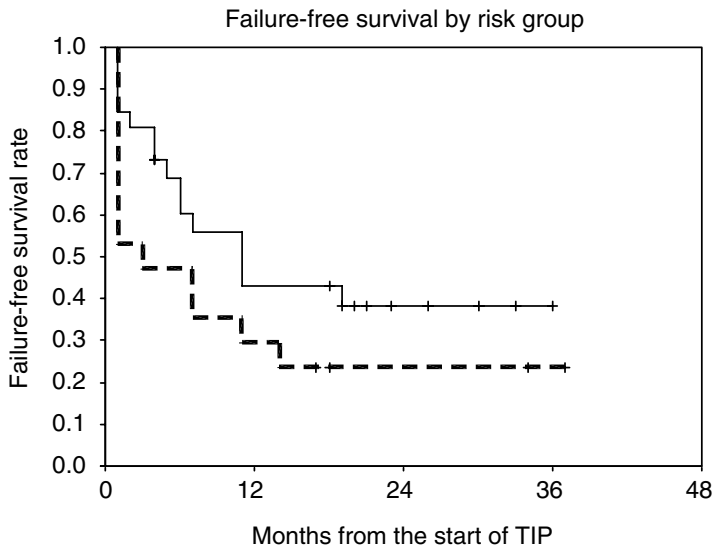

Numbers at risk

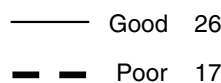

$\begin{array}{ll}10 & 4 \\ 5 & 1\end{array}$

0

0

0

Figure 2 Failure-free survival by risk group.
Overall survival and survival by MSKCC risk groups are shown in Figures 3 and 4 . The overall survival rate at 1 year is $70 \%$ (56-84\%) and the 1-year survival rates for the good- and poor-risk subgroups are $81 \%(64-98 \%)$ and $53 \%(29-77 \%)$, respectively.

Of the nine seminoma patients (five good risk, four poor risk), six are currently alive and disease free (three received additional therapy with radiotherapy and one with high-dose chemotherapy as adjunctive therapy). Of 33 patients with NSGCT, 13 are alive and disease free.

\section{DISCUSSION}

Patients with metastatic GCC developing first progression of active cancer despite initial cisplatin-containing chemotherapy almost all require salvage combination chemotherapy. The exceptions are patients developing late ( $>2$ years) relapse with resectable disease (Baniel et al, 1995; Gerl et al, 1997).

Salvage chemotherapy should be given with curative intent and published series suggest $20-57 \%$ of patients may achieve longterm disease-free status with this and subsequent salvage therapy (Motzer et al, 1991, 2000a, b; Pizzocaro et al, 1992; Miller et al,

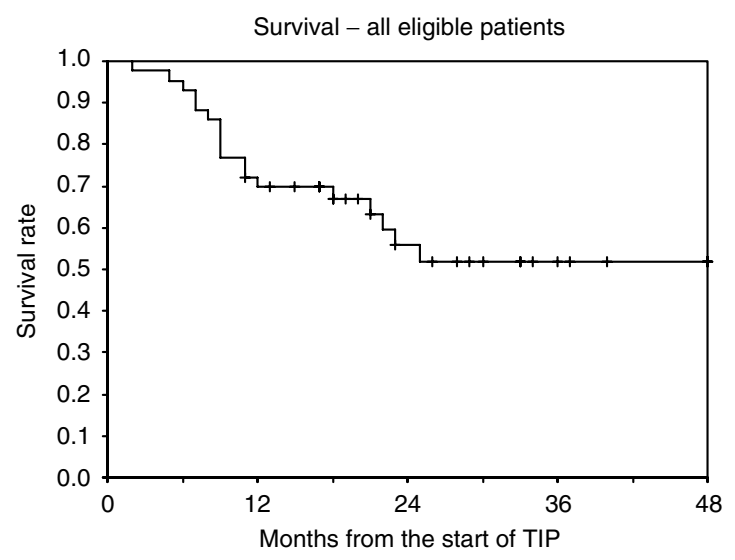

Numbers at risk 43 29 6

Figure 3 Survival, all eligible patients.

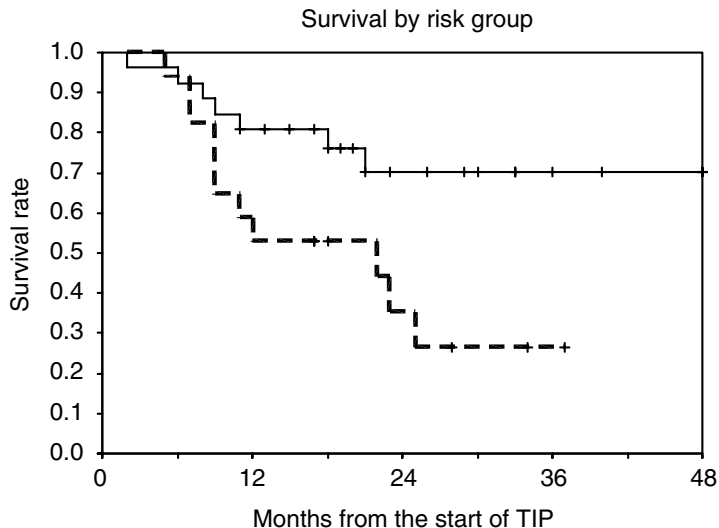

Numbers at risk

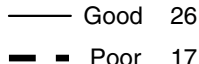

20

10

5

Figure 4 Survival by risk group. 
1997; Bhatia et al, 2000). Prognostic factors associated with an improved outlook include gonadal primary site (Motzer et al, 1991; Pizzocaro et al, 1992; McCaffrey et al, 1997; Loehrer et al, 1998), achievement of initial CR (or $\mathrm{PR}^{-\mathrm{ve}}$ status) with first-line therapy (Motzer et al, 1991; Pizzocaro et al, 1992; Gerl et al, 1995; McCaffrey et al, 1997; Loehrer et al, 1998; Fossa et al, 1999), time to relapse (Baniel et al, 1995; Gerl et al, 1995, 1997; Fossa et al, 1999), low serum markers at relapse (Motzer et al, 1991; Fossa et al, 1999) and (probably) histology, with seminoma favourable (Miller et al, 1997). These factors vary greatly in published salvage series, rendering comparison between regimens impracticable.

Most patients retain cisplatin sensitivity at relapse, and this drug has remained a cornerstone of salvage regimens. In early series, cisplatin was combined with vinblastine (or etoposide) and ifosfamide (VeIP, VIP; Pizzocaro et al, 1992; Farhat et al, 1996; McCaffrey et al, 1997; Miller et al, 1997; Loehrer et al, 1998), and numerous series have reported cure rates of $15-42 \%$ with these combinations used alone or with surgery in patients with NSGCT (Pizzocaro et al, 1992; McCaffrey et al, 1997; Loehrer et al, 1998).

The obvious need to improve these results has yielded two different strategies: the increasing use of new drugs with paclitaxel (Motzer et al, 1994; Bokemeyer et al, 1996; Sandler et al, 1998), gemcitabine (Bokemeyer et al, 1999; Einhorn et al, 1999), oxaliplatin (Kollmannsberger et al, 2002a), irinotecan (Kollmannsberger et al, 2002b; Miki et al, 2002) and epirubicin (Madani et $a l, 2003)$ currently under evaluation as single agents or in combination (Hinton et al, 2002; Miki et al, 2002; Kollmannsberger et al, 2004), and the development of high-dose chemotherapy, particularly since the advent of autologous stem cell rescue and growth factor support (Motzer et al, 1992, 2000a; Beyer et al, 1997; Bhatia et al, 2000; Rosti et al, 2002; Kollmannsberger et al, 2004).

The initial approach to salvage chemotherapy has varied from centre to centre, although the increasing safety of high-dose treatment has led to a number of centres, including Indiana, recommending this as initial salvage treatment. This has the advantage of an increased likelihood of achieving cure compared with third-line or later use of high-dose therapy (Rick et al, 2001), but the disadvantage of poor tolerance of subsequent salvage chemotherapy for the $40-50 \%$ of patients destined to fail this treatment approach (Pont et al, 1997; Beyer et al, 2002). It also represents overtreatment for the $50-60 \%$ of good prognosis patients who would have been cured with standard-dose treatment (Fossa et al, 1999).

One, two or multiple cycles of high-dose therapy using a variety of two or three drug regimens have been used in a phase II setting. However, a single randomised trial (IT94) under the auspices of the European Bone Marrow Transplant Group has provided sobering data (Rosti et al, 2002). A total of 280 patients with cisplatin-sensitive disease were randomised to four cycles of VIP/ VeIP or three cycles of this treatment followed by high-dose chemotherapy with carbopec (high-dose carboplatin, etoposide and cyclophosphamide) with stem cell rescue. The 1-year eventfree survival and 3-year survival (52\% in both arms) were essentially identical.

The alternative approach is standard-dose chemotherapy incorporating newer drugs. The most commonly evaluated regimen is TIP. The MSKCC used this regimen in 30 patients (Motzer et al, 2000b) - now updated to 46 patients (Donadio et al, 2003) - in a good prognosis group but at higher doses than those reported here (paclitaxel $250 \mathrm{mg} \mathrm{m}^{-2}$ by 24 -h infusion, ifosfamide $6 \mathrm{gm} \mathrm{m}^{-2}$ in divided dose) and at higher intensity, as no dose reductions were made and G-CSF was routinely administered. Whereas all patients in the MRC study had failed BEP, the previous treatment given to the MSKCC patients was more heterogeneous and was carboplatin based in two cases.
The MSKCC results were superior when compared with those described here in a broadly comparable, good-risk group with longer follow-up. In the updated study report published to date only in abstract form (Donadio et al, 2003), 46 patients received TIP (41 nonseminoma, five seminoma), 16 in the setting of late relapse. In all, 32 patients achieved CR (70\%) and two $\mathrm{PR}^{-\mathrm{ve}}$, with a total favourable response rate of $74 \%$. Three patients relapsed and with a median follow-up of 52 months, $78 \%$ remain alive. The increased $C R$ rate, and markedly reduced $P R^{-v e}$ rate presumably reflect a greater use of postchemotherapy surgery, although only three patients are recorded as having viable malignancy resected to achieve CR in the updated series.

TIP has also been evaluated by a German group (Porcu et al, 2000). A totoal of 80 patients failing initial or salvage cisplatinbased combination chemotherapy were treated with three cycles of TIP (doses as used by MRC, but ifosfamide $1.2 \mathrm{~g} \mathrm{~m}^{-2}$ i.v. daily $\times 5$ ) with G-CSF support. It was planned that all patients would proceed to high-dose chemotherapy using carboplatin, etoposide and thiotepa. The response rate to TIP was $11 \% \mathrm{CR}$ and $29 \% \mathrm{PR}^{-\mathrm{ve}}$ (total $40 \%$ ). In all, $78 \%$ of patients proceeded to high-dose therapy. With a median follow-up of 3 years, 21 patients (26\%) were failure free with 22 alive $(26 \%)$. This was a more heavily pretreated population than ours. Nonetheless, this seems a disappointing result.

The MSKCC Group have published separate data on the salvage therapy of patients relapsing with a poor prognosis. In total, 37 patients were treated with two cycles of paclitaxel and ifosfamide at 2 -week intervals and accompanied by stem cell harvest. The patients were then treated with three cycles of high-dose carboplatin and etoposide at 14-21 day intervals with stem cell support. Despite the highly adverse prognostic features of this group, $41 \%$ remained failure free at a median follow-up time of $2 \frac{1}{2}$ years. Our results using TIP in a comparable group, with much shorter follow-up, again appeared inferior.

A number of publications are now available describing experience with single agents (Motzer et al, 1994; Bokemeyer et al, 1996, 1999; Sandler et al, 1998; Einhorn et al, 1999; Kollmannsberger et al, 2002a b) or drug combinations (Miki et al, 2002; Hinton et al, 2002; Madani et al, 2003; Kollmannsberger et $a l, 2004)$ in patients with end-stage and cisplatin-refractory disease. Paclitaxel, gemcitabine and oxaliplatin have been evaluated as single agents, and the combinations paclitaxel and gemcitabine (Hinton et al, 2002), oxaliplatin and gemcitabine (Kollmannsberger et al, 2004), cisplatin and irinotecan (Miki et al, 2002) and cisplatin and epirubicin (Madani et al, 2003) as combinations. Comparison of these regimens is not possible because of the heterogeneous nature of the groups treated. However, the achievement of ongoing complete remission in a proportion of cases receiving all four described drug combinations is certainly a provocative finding.

How should contemporary patients relapsing after first-line chemotherapy be treated? There is no definite answer. The single randomised trial showing no benefit to high-dose treatment has been criticised as only one cycle of high-dose treatment was used. Patients in a good prognosis group can still reasonably be treated with standard-dose salvage regimens. Further prospective randomised trials are indicated but would clearly need to be international. Entry of these patients into prospective studies wherever possible is indicated.

In conclusion, our multicentre experience of TIP chemotherapy demonstrates that a substantial proportion of patients, particularly those in the MSKCC favourable group, can achieve long-term FFS. The results of patients with early relapse or those failing to respond satisfactorily to initial BEP are poor and alternative treatment approaches are clearly required. In a future study, we plan to intensify TIP, firstly by avoiding dose reductions by use of growth factors and secondly through the addition of gemcitabine. 


\section{REFERENCES}

Baniel J, Foster RS, Gonin R, Messemer JE, Donohue JP, Einhorn LH (1995) Late relapse of testicular cancer. J Clin Oncol 13: 1170-1176

Beyer J, Kingreen D, Krause M, Schleicher J, Schwaner I, Schwella N, Huhn D, Siegert W (1997) Long term survival of patients with recurrent or refractory germ cell tumors after high dose chemotherapy. Cancer 79: $161-168$

Beyer J, Stenning S, Gerl A, Fossa S, Siegert W (2002) High dose versus conventional-dose chemotherapy as first-salvage treatment in patients with non-seminomatous germ-cell tumors: a matched-pair analysis. Ann Oncol 13: $599-605$

Bhatia S, Abonour R, Porcu P, Seshadri R, Nichols CR, Cornetta K, Einhorn LH (2000) High dose chemotherapy as initial salvage chemotherapy in patients with relapsed testicular cancer. J Clin Oncol 18: $3346-3351$

Bokemeyer C, Bayer J, Metzner B, Ruther U, Harstrick A, Weissbach L, Kohrmann U, Verbeek W, Schmoll HJ (1996) Phase II study of paclitaxel in patients with relapsed or cisplatin-refractory testicular cancer. Ann Oncol 7: $31-34$

Bokemeyer C, Gerl A, Schoffski P, Harstrick A, Niederle N, Beyer J, Casper J, Schmoll HJ, Kanz L (1999) Gemcitabine in patients with relapsed or cisplatin-refractory testicular cancer. J Clin Oncol 17: 12-516

de Wit R, Roberts T, Wilkinson PM, De Mulder P, Mead GM, Fossa SD, Cook P, de Prijk L, Stenning S, Collette L (2001) Equivalence of three or four cycles of bleomycin, etoposide and cisplatin chemotherapy and of a 3- or 5-day schedule in good prognosis germ cell cancer: A randomized study of the European Organization for Research and Treatment of Cancer Genitourinary Tract Cancer Co-operative Group and the Medical Research Council. J Clin Oncol 19: 1629-1640

Donadio AC, Sheinfeld J, Bacik J, Mazumdar M, Marion S, Bajorin DF, Bos GJ, Motzer RJ (2003) Paclitaxel, ifosfamide and cisplatin (TIP): an effective second-line therapy for patients with relapsed testicular germ cell tumours. Proc ASCO (Abstr) 22: 1537

Einhorn LH, Stender MJ, Williams D (1999) Phase II trial of gemcitabine in refractory germ cell tumours. J Clin Oncol 17: 509-511

Farhat F, Culine S, Theodore C, Bekradda M, TerrierLacombe MJ, Droz JP (1996) Cisplatin and ifosfamide with either vinblastine or etoposide as salvage therapy for refractory or relapsing germ cell tumor patients. Cancer 77: 1193 - 1197

Fossa SD, Stenning SP, Gerl A, Horwich A, Clark P, Wilkinson P, Jones W (1999) Prognostic factors in patients progressing after cisplatin-based chemotherapy for malignant non-seminomatous germ cell tumours. Br J Cancer 80: $1392-1399$

Gerl A, Clemm C, Schmeller N, Hartenstein R, Lamerz R, Wilmanns W (1995) Prognosis after salvage treatment for unselected male patients with germ cell tumours. Br J Cancer 72: 1026-1032

Gerl A, Clemm C, Schmeller N, Hentrich M, Lamerz R, Wilmanns W (1997) Late relapse of germ cell tumours after cisplatin-based chemotherapy. Ann Oncol 8: $41-47$

Hinton S, Catalano PJ, Einhorn LH, Nichols CR, Crawford ED, Vogelzang N, Trump D, Loehrer PJ (2002) Phase II study of paclitaxel plus gemcitabine in refractory germ cell tumors (E9897): a trial of the Eastern Co-operative Oncology Group. J Clin Oncol 20: 1859-1863

Kollmannsberger C, Beyer J, Liersch R, Schoeffski P, Metzner B, Rick O, Hartmann JT, Stengele K, Hohloch K, Spott C, Kanz L, Bokemeyer C (2004) Combination chemotherapy with gemcitabine plus oxaliplatin in patients with intensively pretreated or refractory germ cell cancer: A study of the German Testicular Cancer Study Group. J Clin Oncol 22: $108-114$

Kollmannsberger C, Rick O, Derigs HG, Schleucher N, Schoffski P, Beyer J, Schoch R, Sayer HG, Gerl A, Kuczyk M, Spott C, Kanz L, Bokemeyer C (2002a) Activity of oxaliplatin in patients with relapsed or cisplatin refractory germ cell cancer: A study of the German Testicular cancer Study Group. J Clin Oncol 20: 2031-2037

Kollmannsberger C, Rick O, Klaproth H, Kubin T, Sayer HG, Hentrich M, Welslau M, Mayer F, Kuczyk M, Spott C, Kanz L, Bokemeyer C (2002b) Irinotecan in patients with relapsed or cisplatin-refractory germ cell cancer: a phase II study of the German testicular Cancer Study Group. Br J Cancer 87: 729-732
Loehrer PJ, Gonin R, Nichols CR, Weathers T, Einhorn LH (1998) Vinblastine plus ifosfamide plus cisplatin as initial salvage therapy in recurrent germ cell tumour. J Clin Oncol 16: 2500-2504

Madani AA, George DW, Brames JM, Einhorn L (2003) Phase II study of epirubicin plus cisplatin in refractory germ cell tumors. Proc ASCO (Abstr) 22: 388

McCaffrey JA, Mazumdar M, Bajorin D, Bosl GJ, Vlamis V, Motzer RJ (1997) Ifosfamide and cisplatin chemotherapy as first line salvage therapy in germ cell tumors: response and survival. J Clin Oncol 15: $2559-2563$

Miki T, Mizutani Y, Nonomura N, Nomoto T, Nakao M, Saiki S, Kotake T, Okuyama A (2002) Irinotecan plus cisplatin has substantial antitumor effect as salvage chemotherapy against germ cell tumors. Cancer 95: $1879-1885$

Miller KD, Loehrer PJ, Gonin R, Einhorn LH (1997) Salvage chemotherapy with vinblastine, ifosfamide and cisplatin in recurrent seminoma. J Clin Oncol 15: $1427-1431$

Motzer R, Bajorin D, Schwartz L, Hutter H, Bosl G, Scher H, Lyn P, Fischer P, Motzer RJ, Bajorin DF, Schwartz LH (1994) Phase II trial of paclitaxel shows antitumor activity in patients with previously treated germ cell tumors. J Clin Oncol 12: 2277-2283

Motzer R, Gulati S, Crown J, Weisen S, Doherty M, Herr H, Fair W, Sheinfeld J, Sogani P, Russo P, Bosl G (1992) High dose chemotherapy and autologous bone marrow rescue for patients with refractory germ cell tumors. Cancer 69: 550-556

Motzer RJ, Geller NL, Tan CC-Y, Herr H, Morse M, Fair W, Sheinfeld J, Sogani P, Russo P, Bosl G (1991) Salvage chemotherapy for patients with germ cell tumours. The Memorial Sloan-Kettering Cancer center experience (1979-1989). Cancer 67: $1305-1310$

Motzer RJ, Mazumdar M, Sheinfeld J, Bajorin DF, Macapinlac HA, Bains M, Reich L, Flombaum C, Mariani T, Tong WP, Bosl GJ (2000a) Sequential dose intensive paclitaxel, ifosfamide, carboplatin and etoposide salvage therapy for germ cell tumor patients. J Clin Oncol 18: $1173-1180$

Motzer RJ, Sheinfeld J, Mazumdar M, Bains M, Mariani T, Bacik J, Bajorin D, Bosl GJ (2000b) Paclitaxel, ifosfamide and cisplatin second-line therapy for patients with relapsed testicular germ cell cancer. J Clin Oncol 18: $2413-2418$

Pizzocaro G, Salvioni R, Piva L, Faustini M, Nicolai N, Gianni L (1992) Modified cisplatin, etoposide (or vinblastine) and ifosfamide salvage therapy for male germ-cell tumors. Long term results. Ann Oncol 3: $211-216$

Pont J, Bokemeyer C, Harstrick A, Sellner F, Greinix H, Stoiber F (1997) Chemotherapy for germ cell tumors relapsing after high-dose chemotherapy and stem cell support: A retrospective multicenter study of the Austrian Study Group on Urologic Oncology. Ann Oncol 8: $1229-1234$

Porcu P, Bhatia S, Sharma M, Einhorn LH (2000) Results of treatment after relapse from high-dose chemotherapy in germ cell tumors. J Clin Oncol 18: $1181-1186$

Rick O, Bokemeyer C, Beyer J, Hartmann JT, Schwella N, Kingreen D, Neureither S, Metzner B, Casper J, Wandt H, Hartmann F, Schmoll HJ, Derigs G, Gerl A, Berdel WE, Kanz L, Siegert W (2001) Salvage treatment with paclitaxel, ifosfamide, and cisplatin plus high-dose carboplatin, etoposide and thiotepa followed by autologous stem-cell rescue in patients with relapsed or refractory germ cell cancer. J Clin Oncol 19: $81-88$

Rosti G, Pico J, Wandt H, Koza V, Salvioni R, Theodore C, Lelli G (2002) High dose chemotherapy (HDC) in the salvage treatment of patients failing first-line platinum chemotherapy in advanced germ cell tumours (GCT); first results of a prospective randomised trial of the European group for blood and marrow transplantation (EBMT): IT-94 study. Proc ASCO (Abstr) 21: 716

Sandler AB, Cristou A, Fox S, Williams SD, Nichols CR, Turns M, Roth BJ (1998) A phase II trial of paclitaxel in refractory germ cell tumors. Cancer 82: $1381-1386$

\section{Appendix A1}

This study was initiated by the Medical Research Council (now National Cancer Research Institute) Testicular Cancer Group. The principal investigators were Professor M Mason (Cardiff) and Dr GM Mead (Southampton). The trial was coordinated by the 
MRC Clinical Trials Unit, London (formerly the MRC Cancer Trials Office, Cambridge, UK); the senior Clinical Trial Manager was Pat Cook and the trial statistician Sally Stenning. The following centres and clinicians entered patients into the trial:

Southampton General Hospital/Royal South Hants Hospital (10): GM Mead, P Simmonds.

Birmingham Oncology Centre (9): MH Cullen.

Royal Marsden Hospital (7): R Huddart, DP Dearnaley.

Guy's Hospital (5): P Harper.
Cookridge Hospital, Leeds (5): WG Jones (retired). Mt Vernon Hospital (5): GJS Rustin.

Bristol Oncology Centre (2): JD Graham.

Beatson Oncology Centre, Glasgow (2): P Vasey.

Velindre Hospital, Cardiff (1): J Barber, M Mason.

Aberdeen Royal Infirmary (2): D Bissett, A Hutcheon. Leicester Royal Infirmary (1): FJ Madden (retired). Lincoln County Hospital (1): T Sreenivasa.

Walsgrave Hospital, Coventry (1): A Stockdale. Christie Hospital, Manchester (1): PM Wilkinson. 